\title{
Nanoporous graphene oxide membrane and its application in molecular sieving
}

\author{
S. Mahmood Fatemi ${ }^{1,2,}$, Masoud Arabieh ${ }^{1}$ and Hamid Sepehrian ${ }^{1}$ \\ ${ }^{1}$ Computational and Simulation Group, Nuclear Science and Technology Research Institute, Tehran 11365/8486, Iran \\ ${ }^{2}$ Department of Nano Chemistry, School of Chemistry, College of Science, University of Tehran, Tehran, Iran
}

\begin{abstract}
Article Info
Received 12 February 2015 Accepted 3 April 2015

*Corresponding Author

E-mail: mfatemi@aeoi.org.ir m.fatemi@khayam.ut.ac.ir

Tel: +982188221117

\section{Open Access}

DOI: http://dx.doi.org/

10.5714/CL.2015.16.3.183

This is an Open Access article distributed under the terms of the Creative Commons Attribution Non-Commercial License (http://creativecommons.org/licenses/ by-nc/3.0/) which permits unrestricted non-commercial use, distribution, and reproduction in any medium, provided the original work is properly cited.
\end{abstract}

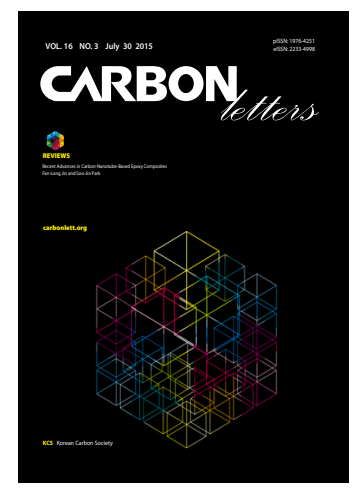

http://carbonlett.org

pISSN: 1976-4251

elSSN: 2233-4998

Copyright $\odot$ Korean Carbon Society

\begin{abstract}
Gas transport through graphene-derived membranes has gained much interest recently due to its promising potential in filtration and separation applications. In this work, we explore $\mathrm{Kr}-85$ gas radionuclide sequestration from natural air in nanoporous graphene oxide membranes in which different sizes and geometries of pores were modeled on the graphene oxide sheet. This was done using atomistic simulations considering mean-squared displacement, diffusion coefficient, number of crossed species of gases through nanoporous graphene oxide, and flow through interlayer galleries. The results showed that the gas features have the densest adsorbed zone in nanoporous graphene oxide, compared with a graphene membrane, and that graphene oxide was more favorable than graphene for $\mathrm{Kr}$ separation. The aim of this paper is to show that for the well-defined pore size called P-7, it is possible to separate $\mathrm{Kr}-85$ from a gas mixture containing $\mathrm{Kr}-85, \mathrm{O}_{2}$ and $\mathrm{N}_{2}$. The results would benefit the oil industry among others.
\end{abstract}

Key words: molecular dynamic simulation, nanoporous graphene oxide membrane, separation, diffusion coefficient

\section{Introduction}

$\mathrm{Kr}-85$ is a radioactive gas released to the atmosphere by nuclear explosions, nuclear power plants, volcanoes, and earthquakes. The major source of $\mathrm{Kr}-85$ is nuclear fission in nuclear reactors and nuclear weapon tests. It is worth mentioning that, as a result of nuclear weapon tests from 1945 through 1962, an estimated 5 million curies of $\mathrm{Kr}-85$ were released to the atmosphere. This radionuclide is odorless, colorless, and tasteless; and emits low levels of both gamma and beta radiation [1]. It is used in gas mixtures with argon or xenon to improve ionization in light bulbs by reducing their starting voltage. This radionuclide is also used in plasma displays, spark gaps, and leak detection. The most important concerns occur when a very small amount of $\mathrm{Kr}-85$ is taken into the body, dissolved in the blood stream, and distributed to the organs and tissues throughout the whole body. The tissue most affected by beta particles emitted from $\mathrm{Kr}-85$ radioactive decay, is the skin. Unfortunately, $\mathrm{Kr}-85$ does not generally participate in any chemical separation processes due to its fully occupied electronic valance shell. Separation of such an important gas is an interesting subject for scientific investigation.

Separation of gas mixtures using nanoporous materials is an emerging field of research with great potential such as gas sensor and gas purification applications. The materials that are currently being investigated for these applications include zeolites [2], silica [3], carbon [4], and polymers [5]. These membranes all have the key properties of chemical resistance and thermal stability. Graphene, an atomically thin single sheet of graphite comprising $\mathrm{sp}^{2}$ bonded carbon atoms arranged in a hexagonal lattice [6], holds significant promise for gas separation due to its unique properties. Pristine graphene has been shown to be imperme- 
able to gases [7]. However, several studies have suggested that graphene has the potential to induce highly selective transport by generation of pore defects [8-14], in which atoms can be removed from the graphene lattice to create pores of specific size and geometry.

Despite the simple architecture of such molecular sieves, the experimental set-up remains challenging. Drilling such delicate nanopores on single graphene sheets is one of the challenges in current research on molecular sieves, as is detection of single molecules (e.g., for DNA sequencing) [15]. For example, UVinduced oxidative etching [16] can create pores in micrometersized graphene membranes and the resulting membranes could be used as molecular sieves. Jiang et al. [10] designed two oneatom-thin porous membranes for gas separation by simulation and modeling, and computed diffusion barriers. They estimated $\mathrm{H}_{2} / \mathrm{CH}_{4}$ selectivity on the order of $10^{8}$ and $10^{23}$ for the N-functionalized, and all-H pores, respectively. First principles molecular dynamics simulations indicate a high flux of $\mathrm{H}_{2}$ through the $\mathrm{N}$-functionalized pores in a graphene membrane, which is in accord with the relatively low $\mathrm{H}_{2}$ diffusion barriers. Blankenburg et al. [13] proposed and characterized a one-atom-thick membrane for atmospheric gas separation. They performed simulation and modeling calculations for different atmospheric gas molecules entering the membrane pores. The determined separabilities for hydrogen and helium ranged from $10^{3}$ up to $10^{23}$ at room temperature, with a permeance greater than $10^{-6} \mathrm{~m}^{-2}$ $\mathrm{s}^{-1} \mathrm{~Pa}^{-1}$, which is superior to those of classical membranes. They proposed that such membranes show high hydrogen and helium selectivity and could be useful for membranes in fuel cells or gas sensors, for separation of $\mathrm{CO}, \mathrm{CO}_{2}$, or ammonia, as well as for extraction of helium.

After that; Koenig et al. [17] investigated the transport of a variety of gases $\left(\mathrm{H}_{2}, \mathrm{CO}_{2}, \mathrm{Ar}, \mathrm{N}_{2}, \mathrm{CH}_{4}\right.$, and $\left.\mathrm{SF}_{6}\right)$ through the pores and compared their results with those of Blankenburg et al. [13] and Jiang et al. [10] Koenig et al. [17] found a $\mathrm{H}_{2}$ leakrate on the order of $\sim 10^{-20} \mathrm{~mol} \mathrm{~s}^{-1} \mathrm{~Pa}^{-1}$ for a H-passivated pore in graphene consisting of two missing benzene rings at room temperature. The similarity in the $\mathrm{H}_{2}$ leakage reported in the previously mentioned work suggests a $\mathrm{H}_{2}$ energy barrier to pore entry.

Recent advances in molecular simulation make it possible to study these systems at atomic resolutions. Based on the aforementioned reasons, at the moment, we suppose that validating the results of such delicate simulations is impossible by experiment; however, we expect that our results might motivate experimental research to validate these results in the near future.

Graphene oxide (GO) is a chemically modified graphene with oxygen-containing functional groups (e.g., hydroxyl, carbonyl, epoxy, and carboxyl groups) on the graphene basal plane [18]. In recent years, it has become one of the most studied nanomaterials [19-24]. GO has a long history, dating back to at least 1859, when Brodie reported its synthesis [19]. Despite this history, the structure of GO is still under debate. GO based materials have generated incredible interest for energy-related applications because of its multifunctional flexibility $[25,26]$. Moreover, GO has recently been studied for various biological applications [27], and has been applied in areas such as fabrication of intercalated GO composites [28]. Recent studies showed that successful separation of gas mixtures using GO-based membranes, represents remarkable po-



Fig. 1. Right side: cross-sectional view, left side: lateral view of graphene oxide. Colors assigned to each molecule: green (carbon); red (oxygen), white (hydrogen).

tential of GO in the field of gas separation [29-33]. Considering the theoretical surface area of graphene $\left(2630 \mathrm{~m}^{2} / \mathrm{g}\right)$ [34] and the hydrophilic surface of GO, it is expected to have huge space in which to store polar and hydrophilic gas molecules. This space could be used for storage and separation of hydrophilic gas. Despite the enormous potential for applications of GO, improvements in porosity and surface area are rarely found for gas separation applications. Separation processes based on membranes, depend on several properties, including pore size, stable structure, and appropriate permeability. The porosity and accessible surface area can easily be tuned for electrochemical, gas storage/separation, and catalytic ability by changing the spacing in the graphene layer, or by functionalizing with various chemical groups. For example Kim et al. [31] reported highly permeable and selective GO membranes for separating mixtures of gases of industrial relevance. They focused on the gas-transport properties of thin defective graphene and GO membranes, and reported that graphene itself displays outstanding gas separation properties. However, to the best of our knowledge, molecular sieving of radionuclide gas by nanoporous GO (NPGO) has never been reported. Demonstration of this capability is fundamental knowledge for further application of NPGO for gas separation. A popular structural model of GO, shown in Fig. 1, was proposed by Guo et al. [35]: an equilateral triangle formed by three $\mathrm{C}_{8} \mathrm{O}_{2}$ $(\mathrm{OH})_{2}$ units. In this model the $\mathrm{C}_{8} \mathrm{O}_{2}(\mathrm{OH})_{2}$ units are homogeneously distributed on the carbon sheet. Each $\mathrm{C}_{8} \mathrm{O}_{2}(\mathrm{OH})_{2}$ unit contains two para-epoxy groups at opposite sides of the carbon plane, and two para-hydroxyl groups above the plane of the carbons.

\section{Simulation Details and Methods}

Molecular permeation of three different gases (namely $\mathrm{Kr}-85$, $\mathrm{O}_{2}$, and $\mathrm{N}_{2}$ ) through NPGO with different pore sizes was simulated based on a molecular dynamic approach. For simplicity, hereafter $\mathrm{Kr}$ is used to represent ${ }^{85} \mathrm{Kr}$. All molecular dynamic simulations were performed using the large-scale atomic/molecular massively parallel simulator (LAMMPS) package [36] and structures were visualized using the visual molecular dynamics (VMD) package [37]. The all-atom optimized potentials for liquid simulations (OPLS-AA) was used for GO, which is able to capture essential many-body terms in inter-atomic interactions (i.e., bond stretching, bond angle bending, van der Waals, electrostatic interactions, and partial charges) [38]. All molecular dynamic simulations were performed in an NVT en- 
semble for $10 \mathrm{~ns}$. The Nose-Hoover barostat and thermostat [39] were applied to maintain the pressure and temperature at $1 \mathrm{~atm}$ and $300 \mathrm{~K}$, with damping coefficients $1 \mathrm{ps}^{-1}$ and $0.1 \mathrm{ps}^{-1}$, respectively, and time steps of $0.5 \mathrm{fs}$ were used during all molecular dynamic simulations. Energy minimization was performed to find the thermally stable morphology and to achieve a conformation with the minimum potential energy for all molecules. Non-bonded van-der-Waals interactions were modeled in terms of 12-6 Lennard-Jones famous potentials [40] with a cut-off distance of $1.2 \mathrm{~nm}$, that is:

$$
U_{L J}\left(r_{i j}\right)=\sum_{j>i} 4 \varepsilon_{i j}\left[\left(\frac{\sigma_{i j}}{r_{i j}}\right)^{12}-\left(\frac{\sigma_{i j}}{r_{i j}}\right)^{6}\right]
$$

The parameters used for non-bond interactions are given in Table $1[41,42]$. The SHAKE algorithm was applied for the stretching terms between oxygen and hydrogen atoms of GO to reduce high-frequency vibrations that require shorter time steps [43]. The particle mesh Ewald (PME) [44] method with a 10.0 $\AA$ real-space cutoff, $1.5 \AA$ reciprocal space gridding, and splines

\begin{tabular}{ccccc} 
Table 1. Parameters used for nonbonding interactions & \\
\hline Species of atoms & $\varepsilon_{\mathrm{i}}(\mathrm{kcal} / \mathrm{mol})$ & $\sigma_{\mathrm{i}}(\AA)$ & $\mathrm{q}(\mathrm{e})$ & $\mathrm{m}(\mathrm{au})$ \\
\hline Nitrogen $^{\mathrm{a})}$ & 0.1819 & 3.680 & 0 & 14.006 \\
Oxygen $^{\mathrm{a})}$ & 0.2246 & 3.430 & 0 & 15.999 \\
$\mathrm{Kr}^{\mathrm{b})}$ & 0.3170 & 3.624 & 0 & 85.000 \\
Carbon $^{\mathrm{b})}$ & 0.0700 & 3.550 & 0 & 12.011 \\
\hline
\end{tabular}

Data are given from ${ }^{\text {a) }}[42]$ and ${ }^{\text {b) }}[41]$ on the order of ' 4 ' with a $10^{-5}$ tolerance was implemented to compute the electrostatic interactions. A simulation box with the dimensions of $30 \times 30 \times 80 \AA$ was constructed and a NPGO membrane was placed in the middle of the box at Cartesian coordinate origin $(0,0,0)$ as the separator, dividing the simulation box with the height of $4 \mathrm{~nm}$ into two equal volume chambers, right and left chambers for all molecular dynamic simulation (Fig. 2). Initially, an equal number of 15 species of gases of $\mathrm{Kr}$, $\mathrm{O}_{2}$ and $\mathrm{N}_{2}$ were loaded into the right chamber (see Fig. 2), while the other side (left chamber) was vacuum for all molecular dy-



Fig. 3. The nanoporous graphene oxide $(G O)$ model with three $\mathrm{C}_{8} \mathrm{O}_{2}$ $(\mathrm{OH})_{2}$ units on the carbon plane. The blue dotted lines indicate the unit cell of the porous $\mathrm{GO}$, and the red dotted lines show the equilateral triangle formed by three $\mathrm{C}_{8} \mathrm{O}_{2}(\mathrm{OH})_{2}$ units.

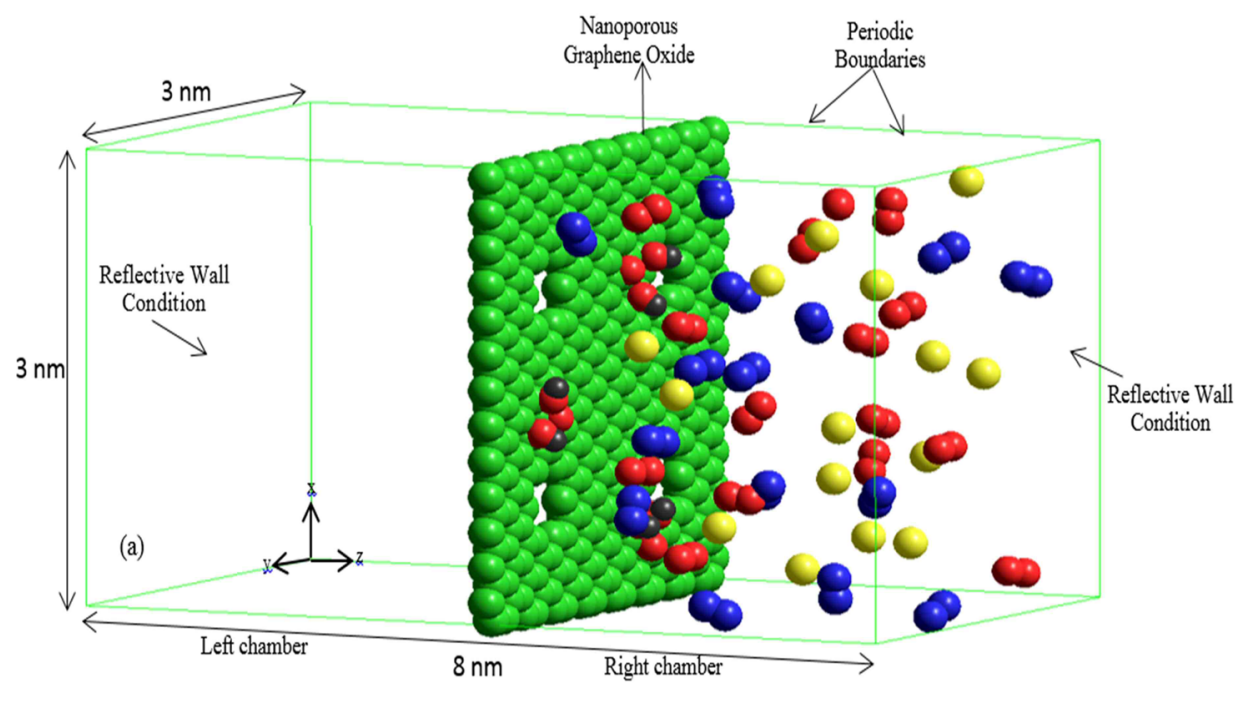

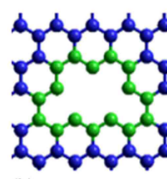

(b)

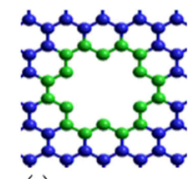

(c)



(d)

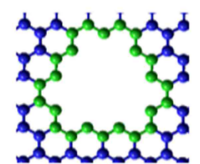

(e)

Fig. 2. (a) Initial MD snapshot of the gases loaded into the right chamber and structures of the nanopores employed in the simulation, (b) P-5, (c) P-7, (d) $\mathrm{P}-10,(\mathrm{e}) \mathrm{P}-12$. Colors assigned to each molecules/atoms: red $\left(\mathrm{O}_{2}\right)$, yellow $(\mathrm{Kr})$, blue $\left(\mathrm{N}_{2}\right)$, green $(\mathrm{C})$, and black $(\mathrm{H})$. 
namic simulations.

To construct the NPGO membrane, four pores on the GO sheet were regarded as a unit cell, and the NPGO model had three $\mathrm{C}_{8} \mathrm{O}_{2}$ $(\mathrm{OH})_{2}$ units on the carbon plane, as can be seen in Fig. 3. Reflective boundary conditions were applied in the z-direction of the simulation box (normal to the graphene plane) while periodic boundary conditions were considered in the other two directions [45]. To avoid vertical displacement of the entire NPGO membrane, the NPGO was frozen during the simulation. Nanopores were created by selectively removing atoms from the GO sheet. Various sizes of pores were considered, which were called by the number of graphene ring units removed or partially opened (i.e., P-5 (P-5), P-7, P-10 and P-12; see Fig. 2). As shown in Fig. 2b-e, some carbon atoms of the single layer $\mathrm{GO}$ were arbitrarily removed to generate an axially symmetric shape of the nanopores. Some pores (P-7 and $\mathrm{P}-10$ ) were fabricated by removing carbon atoms whose coordinates fulfilled the condition $\sqrt{x^{2}+y^{2}} \leq r$, circle equation, where " $\mathrm{r}$ " is the radius of the pore. Moreover, $\mathrm{x}$, and $\mathrm{y}$ are the Cartesian coordinates of atoms, with respect to the origin of the coordinate system. The other pores were constructed by removing carbon atoms to build the noted pore, without any specific equation. The fabrication procedure for all nanopores was conducted using the VMD package [37].

\section{Results and Discussion}

\subsection{The mean-squared displacement analysis}

The results of mean-squared displacement (MSD) calculations pertaining to the titled gases at $\mathrm{P}-5, \mathrm{P}-7$, and $\mathrm{P}-10 \mathrm{GO}$ pore sizes are displayed in Figs. 4-6, respectively. As can be seen, none of the species of the gases could cross the NPGO membrane through P-5, because the size of these pores was smaller than the kinetic diameter of all species of gases (Fig. 4). Because the pore size was very small, three gases were confined to the right chamber. They have some non-zero value for MSD.

Fig. 5 shows the calculated MSD versus time in the P-7 GO membrane. As can be seen obviously in Fig. 7, only $\mathrm{Kr}$ could cross the nanoporous graphene membrane through P-7 due to a pore size adequate for the entry of $\mathrm{Kr}$ atoms. For NPGO with



Fig. 4. Calculated mean-squared displacement in relation to time for $\mathrm{Kr}$ $\mathrm{N}_{2}$, and $\mathrm{O}_{2}$ in the $\mathrm{P}-5$ graphene oxide membrane. this pore size, it can be concluded that molecular sieving occurred and that $\mathrm{Kr}$ gas was separated selectively from the gas mixture, whereas the size and shape of the pores restricted the permeation of the nitrogen and oxygen molecules. The corresponding simulation snapshots of molecular sieving of $\mathrm{Kr}$ atoms are shown in Fig. 7. Fig. 6 shows the calculated MSD versus time in a $\mathrm{P}-10 \mathrm{GO}$ membrane. As expected, increasing the pore size to $\mathrm{P}-10$, removed the restrictions and all the gases were able to pass through the graphene membrane.

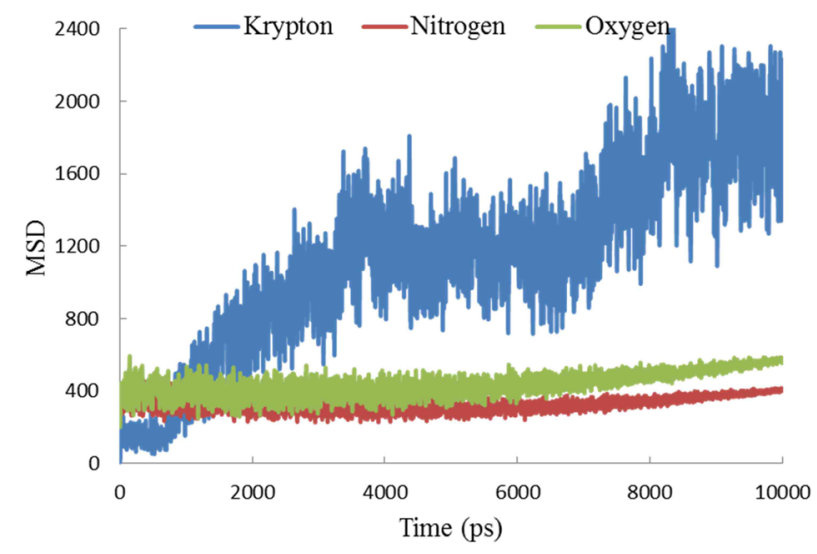

Fig. 5. Calculated mean-squared displacement in relation to time for $\mathrm{K}$ $\mathrm{N}_{2}$, and $\mathrm{O}_{2}$ in the $\mathrm{P}-7$ graphene oxide membrane.

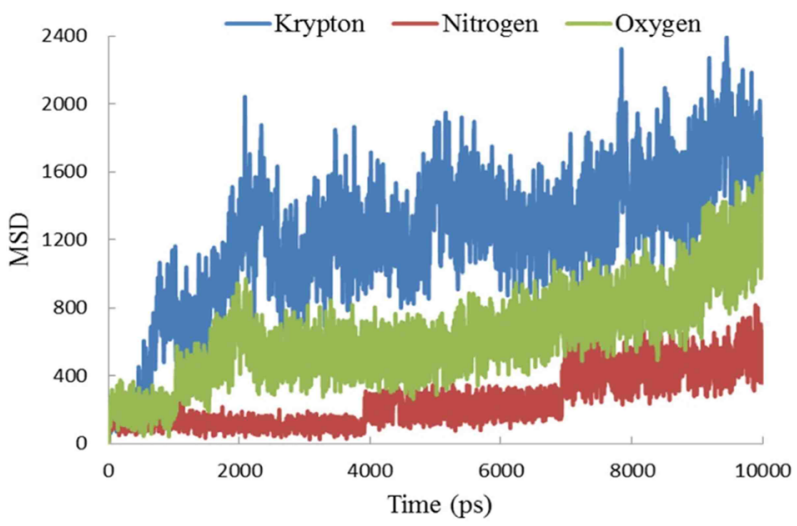

Fig. 6. Calculated mean-squared displacement in relation to time for $\mathrm{Kr}$ $\mathrm{N}_{2}$, and $\mathrm{O}_{2}$ in the $\mathrm{P}-10$ graphene oxide membrane.



Fig. 7. Snapshot of the gases passing through P-7 nanoporous graphene oxide, colors assigned to each molecule/atom: red $\left(\mathrm{O}_{2}\right)$, yellow $(\mathrm{Kr})$, blue $\left(\mathrm{N}_{2}\right)$, green $(\mathrm{C})$, and black $(\mathrm{H})$ 
Table 2. Calculated coefficient diffusions for $\mathrm{Kr}_{1} \mathrm{~N}_{2}$ and $\mathrm{O}_{2}$ at various pore sizes

\begin{tabular}{cccc} 
Molecule/atom & $\mathrm{P}-5$ & $\mathrm{P}-7$ & $\mathrm{P}-10$ \\
\hline $\mathrm{Kr}$ & 0.000 & 0.394 & 0.216 \\
$\mathrm{O}_{2}$ & 0.000 & 0.000 & 0.152 \\
$\mathrm{~N}_{2}$ & 0.000 & 0.000 & 0.088 \\
\hline
\end{tabular}

\subsection{The comparison of diffusion coefficients}

Using MD trajectories, the diffusion coefficients of $\mathrm{Kr}$ and di-atomic gases through the various rings of the NPGO membrane could be calculated from the limiting slope of the MSD curve against time using the Einstein relation [46]. This equation relates the long-time ( $t$ ) limit of MSD of the particles to diffusivity, D, through

$$
3 D=\lim _{t \rightarrow \infty} \frac{(M S D(t))}{2 t}
$$

Where $M S D(t)=\left\langle\left|r_{i}(t)-r_{i}(0)^{2}\right|\right\rangle$. In this equation, the angular brackets indicate an ensemble average over atoms in the system and over time origins, and $r_{i}$ is the center of the mass coordinates of NPGO. Diffusion coefficients $\left(\AA^{2} / \mathrm{ps}\right)$ for titled gases can be calculated using MSD versus time graphs. These quantities are summarized in Table 2. The results showed that: 1) no gases passed through the NPGO membrane with P-5, which was in contrast to the case of P-10, 2) P-7 was preferable to $\mathrm{P}-10$ for separation of $\mathrm{Kr}$. These values indicate that P-7 GO membranes are good candidates for the selective separation of $\mathrm{Kr}$ from other air components.

\subsection{Number of species of gases passed through the NPGO membrane}

To find the effect of the pore size on the number of gas species passing through the NPGO membrane, the number of gases passing the NPGO membrane was calculated. Fig. 8 shows the total number of gases crossed, versus time, for $\mathrm{Kr}, \mathrm{N}_{2}$, and $\mathrm{O}_{2}$

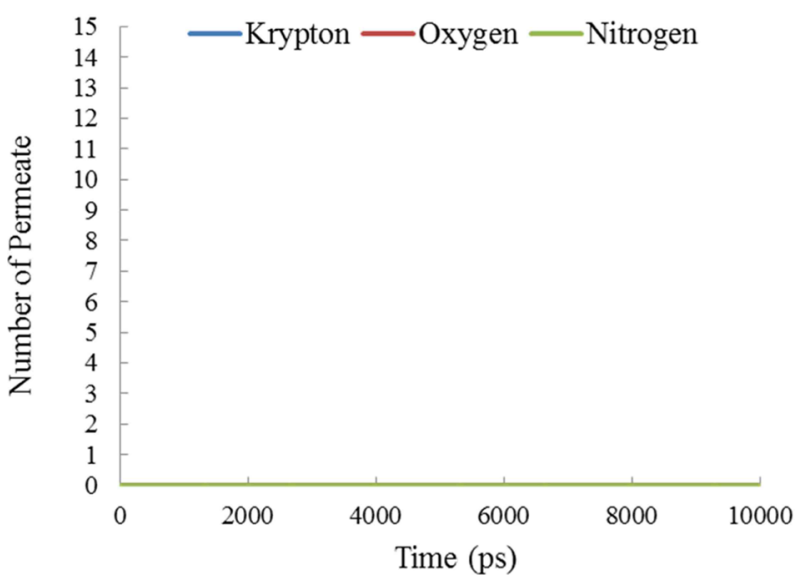

Fig. 8. Total number of gases crossed through the nanoporous graphene oxide membrane in relation to time for $\mathrm{Kr}, \mathrm{N}_{2}$, and $\mathrm{O}_{2}$ in the $\mathrm{P}-5$ membrane. through a P-5 NPGO membrane.

Graphene is an excellent starting point for developing size selective membranes [47] because of its atomic thickness and impermeability to all gases $[48,49]$. However, this means that pores that can exclude larger molecules, but allow smaller molecules to pass through, have to be introduced into the material. In Fig. 8 , the size of the pores is much smaller than the molecular size of all the investigated gases. Therefore, none of the species of gases could cross the P-5 NPGO membrane, and both the fluctuations and the value of graphs are zero.

When the pore size was increased to P-7, $\mathrm{O}_{2}$ and $\mathrm{N}_{2}$ molecules could not cross the membrane. Fig. 9 shows the total numbers of crossed gases versus time for $\mathrm{Kr}, \mathrm{N}_{2}$, and $\mathrm{O}_{2}$ for P-7 NPGO. Fig. 10 shows the typical trajectory of gas separation; and finally, molecular sieving of Kr occurred for P-7 NPGO during 10000 ps of simulation time. Fig. 11 shows the total number of crossed gases versus time for $\mathrm{Kr}_{2} \mathrm{~N}_{2}$ and $\mathrm{O}_{2}$ in the P-10 NPGO. For pores at the size of P-10, all three gases could cross the NPGO membrane; whereas, $\mathrm{P}-7$ only allowed $\mathrm{Kr}$ atoms to permeate. In the case of $\mathrm{O}_{2}$ and $\mathrm{N}_{2}$, the restriction of the molecular orientation largely prohibited permeation. When nitrogen and oxygen molecules were not blocked by the size of the pores (i.e., P-10), more oxygen molecules passed through the NPGO membrane than nitrogen molecules. This might be related to a lower po-

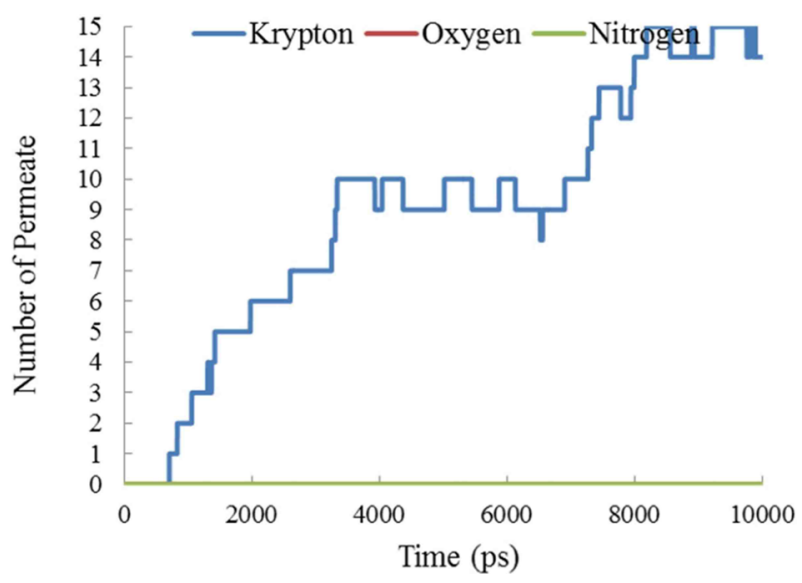

Fig. 9. Total number of gases crossed through nanoporous graphene oxide membrane in relation to time for $\mathrm{Kr}_{1} \mathrm{~N}_{2}$, and $\mathrm{O}_{2}$ in the P-7 membrane.

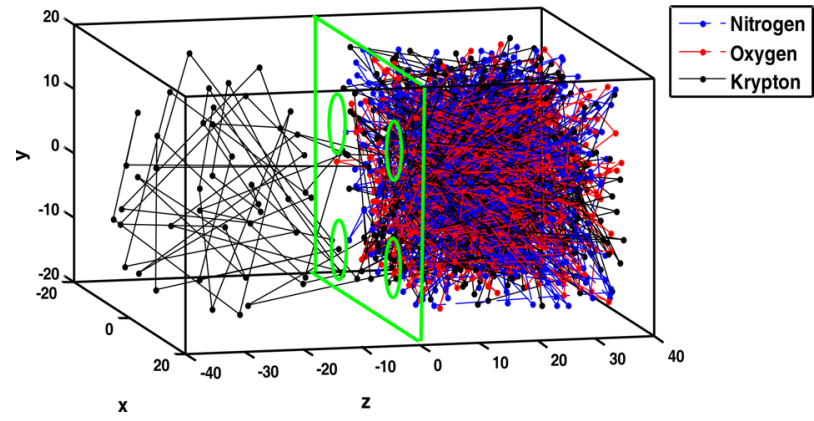

Fig. 10. Typical trajectory of gas separation with final molecular sieving of $\mathrm{Kr}$ for the P-7 nanoporous graphene oxide, during 10000 ps of simulation time. 


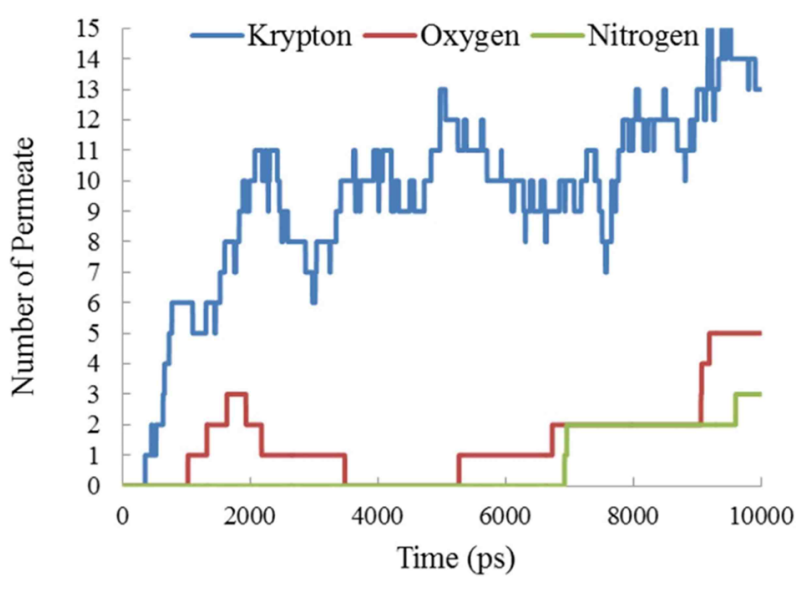

Fig. 11. Total number of gases crossed through the nanoporous graphene oxide membrane in relation to time for $\mathrm{Kr}_{2} \mathrm{~N}_{2}$ and $\mathrm{O}_{2}$ in the $\mathrm{P}-10$ membrane.

\begin{tabular}{|c|c|c|c|c|}
\hline Nanoporous & P-5 & P-7 & P-10 & $\mathrm{P}-12$ \\
\hline Size $(\AA)$ & 5.80 & 6.51 & 7.74 & 8.59 \\
\hline Area $\left(\AA^{2}\right)$ & 23.42 & 32.79 & 46.84 & 56.20 \\
\hline Kr-passage & 0 & 14 & 13 & 10 \\
\hline $\mathrm{O}_{2}$ - passage & 0 & 0 & 5 & 8 \\
\hline $\mathrm{N}_{2}$-passage & 0 & 0 & 3 & 5 \\
\hline $\mathrm{S}_{8 S_{K} \mathrm{~J}} / \mathrm{O}_{2}$ & $0 \%$ & $100 \%$ & $77 \%$ & $20 \%$ \\
\hline $\mathrm{S}_{85_{K}} /_{N_{2}}$ & $0 \%$ & $100 \%$ & $61 \%$ & $50 \%$ \\
\hline
\end{tabular}

NPGO: nanoporous graphene oxide.

tential barrier of permeation for oxygen molecules. Permeation events were calculated in Table 3.

As shown in Table 3, no gas was observed to permeate through P-5 during $10 \mathrm{~ns}$ simulation, while $\mathrm{Kr}$ atoms of P-7 went through the pores. This issue was completely due to the pore size restriction as P-7 pores were too small for nitrogen and oxygen to get through, but large enough for $\mathrm{Kr}$. In this way, $\mathrm{Kr}$ atoms can be completely separated from nitrogen and oxygen molecules by P-7 NPGO. For pore size P-10, during 10 ns of simulation, thirteen $\mathrm{Kr}$ atoms passed through pores, while the corresponding number of oxygen and nitrogen molecules was five and three, respectively. For pore size P-12, more nitrogen and oxygen molecules, and fewer $\mathrm{Kr}$ molecules, permeated than with P-10. Moreover, the number of oxygen molecules permeating the P-12 membrane increased and exceeded that of nitrogen molecules. For pore size P-12, still more oxygen molecules permeated the membrane than did nitrogen. Also, the configurations of oxygen and nitrogen molecules placed at the center of the pore were different. The permeation ratio, defined as the ratio of the numbers of permeation events of the two types of gas molecules, could be used to describe the selectivity of the membrane. Here, the permeation ratio is reported as $\mathrm{Kr} / \mathrm{O}_{2}$ and $\mathrm{Kr} / \mathrm{N}_{2}$ permeations. A higher permeation ratio means better selectivity

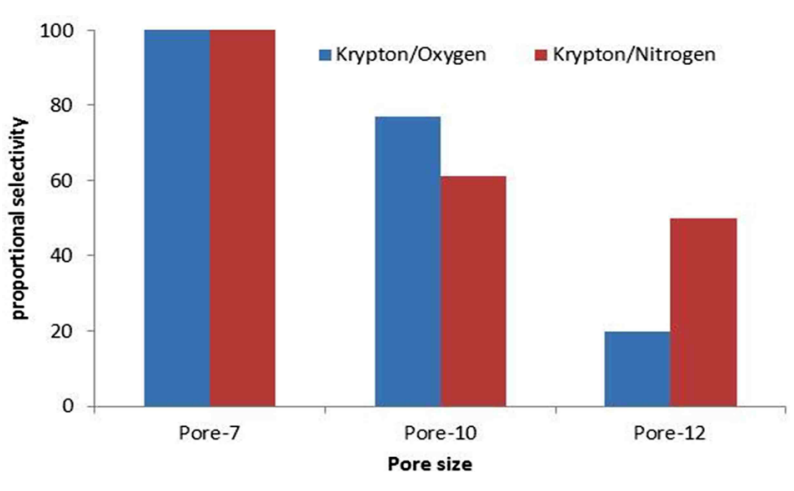

Fig. 12. Proportional selectivity of $\mathrm{Kr}$ from the gas mixture.

of the NPGO membrane. If the permeation ratio is equal to one, there is no selectivity. Maximum $\mathrm{Kr} / \mathrm{O}_{2}$ and $\mathrm{Kr} / \mathrm{N}_{2}$ permeation ratios were observed for P-7 membranes. The $\mathrm{Kr} / \mathrm{O}_{2}$ and $\mathrm{Kr} / \mathrm{N}_{2}$ ratios decreased as the pore size increased, until P-12.

Fig. 12 shows proportional selectivity of $\mathrm{Kr}$ from the gas mixture. As Fig. 12 shows, when the well-defined pore size P-7 was selected, $\mathrm{Kr}$ yield and selectivity were remarkable (to the maximum of $100 \%$ ). With larger pore sizes, $\mathrm{Kr}$ yield and selectivity decreased according to pore size such that for P-10 and $\mathrm{P}-12$, with pore area of 46.84 and $56.20\left(\AA^{2}\right)$, the $\mathrm{Kr}$ yield and selectivity were $62 \%$ and $43 \%$, respectively.

Preliminary results indicate an additional approach might further increase $\mathrm{Kr}$ gas separation. Fig. 12 indicates that there is discrimination between $\mathrm{Kr}$ gas and the $\mathrm{O}_{2} / \mathrm{N}_{2}$ mixture, as applied gases which contribute to higher separation selectivity in P-7. It is concluded that more carefully defined pore size could intensify separation of $\mathrm{Kr}$ gas from the mixture. Thus the proper pore size actually plays a key role in the enhancement of selectivity for $\mathrm{Kr}$.

\subsection{Calculating the flow of gases}

The flow is used to characterize the membrane permeability quantitatively, and is defined as:

$$
F=\frac{N(m o l)}{S\left(m^{2}\right) T(s)}
$$

Where $\mathrm{N}$ is the moles of gases that permeated through the NPGO membrane, S refers to the total area of the nanoporous

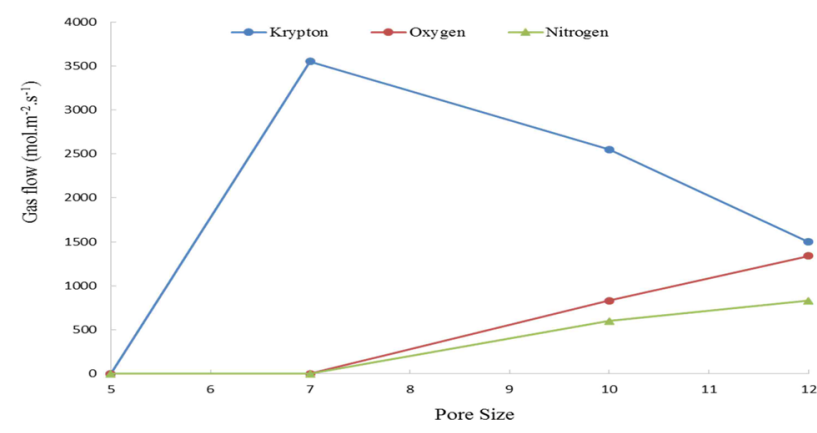

Fig. 13. Flow of gases passing through the nanoporous graphene oxide membranes for pores of different area. 


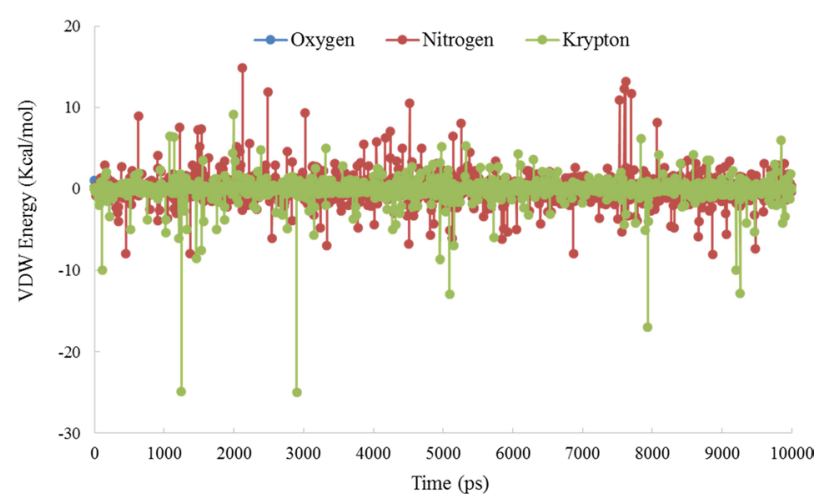

Fig. 14. VDW energy between the gas species and edge atoms of P-7 pores in nanoporous graphene oxide membranes.



Fig. 15. Schematic adsorption onto the graphene oxide surface as a function of the distance from the membrane graphene oxide nanopore $(z$ $=0)$.

membrane, and $\mathrm{T}$ is the time. The flow of $\mathrm{Kr}, \mathrm{O}_{2}$, and $\mathrm{N}_{2}$ was calculated for the various pore-size models, as shown in Fig. 13. There was a prodigious increase in the flow of $\mathrm{Kr}$ atoms near the pore size of $\mathrm{P}-7$, where restrictions related to the size and shape of the pores to $\mathrm{Kr}$ permeation began to vanish. At larger pore sizes, the flow of $\mathrm{Kr}$ atoms became reduced. In the case of the nitrogen and oxygen molecules, flow increased as the pore area increased.

\subsection{Van der Waals interaction}

The van der Waals interactions between gas molecules and the atoms at the edges of pores in the NPGO membrane were also calculated, and are shown in Fig. 14. As shown there, the VDW energy between the $\mathrm{Kr}$ gases and edge atoms of the P-7 NPGO was more negative than for oxygen and nitrogen. This caused transit of $\mathrm{Kr}$ gases through the NPGO membrane, which resulted in more Kr-permeation events than for oxygen and nitrogen.

\subsection{Compare porous graphene and GO nano- pores}

Results of simulation showed that $\mathrm{N}_{2}$ gas is strongly adsorbed onto NPGO, thus forming an adsorbed layer that can contribute to comparison of graphene and GO membranes. Fig. 15 shows schematic adsorption onto the NPGO surface as a function of the distance from the membrane GO nanopore $(z=0)$. Nitrogen features strong adsorption layers, while oxygen and krypton are significantly less attracted by the NPGO membrane. In order to analyze the relative contribution of the bulk (gas phase) and adsorbed layer to compare graphene and NPGO membranes, we divided each chamber into two different zones along the z-direction, namely the adsorption and the bulk zone (gas phase). We defined the adsorption zones as the regions $2 \AA<|z|<7 \AA$ and the bulk zones as the regions $7 \AA<|z|<40 \AA$, as shown in Fig. 15. To compare graphene and GO membranes, the probability density of finding molecules of each of the gases involved in this study, was calculated as a function of the distance from the membrane.

Regarding the placement of $\mathrm{C}_{8} \mathrm{O}_{2}(\mathrm{OH})_{2}$ on the graphene sheet; two $\mathrm{C}_{8} \mathrm{O}_{2}(\mathrm{OH})_{2}$ molecules are close to two pores while the other $\mathrm{C}_{8} \mathrm{O}_{2}(\mathrm{OH})_{2}$ is in the middle of the other two pores. Thus, two pores are influenced by $\mathrm{C}_{8} \mathrm{O}_{2}(\mathrm{OH})_{2}$ while the other two pores are without such influence. As a whole, the results showed that the gas features involved in this study have the densest adsorbed zone in NPGO, compare with a graphene membrane. The adsorbed zone is defined as the number of gas particles divided by the volume of the simulation box. The gas density was calculated by considering only the particles in the adsorption zone ( 2 $\AA<|\mathrm{z}|<7 \AA$ ) and the volume available to them. The probability density by simulation was $1.6 \%, 14.4 \%$, and $18.2 \%$ (for, $\mathrm{Kr}, \mathrm{O}_{2}$, and $\mathrm{N}_{2}$ respectively for graphene); and $2.1 \%, 27.4 \%$, and $39.5 \%$ (for $\mathrm{Kr}, \mathrm{O}_{2}$, and $\mathrm{N}_{2}$ respectively for $\mathrm{GO}$ ). This means that more molecules cross through NPGO than through porous graphene.

\section{Conclusions}

Using simulations of molecular dynamics, we showed that NPGO membranes could be applied to separate $\mathrm{Kr}-85$ gas radionuclides from natural air. The results of the simulation showed that separation of $\mathrm{Kr}-85$ from air could best be achieved using pore size $\mathrm{P}-7$, which was barely larger than the $\mathrm{Kr}-85$ gas radionuclides, and was smaller than the nitrogen and oxygen molecules. Thus P-7 pores were too small for nitrogen and oxygen molecules to get through, but large enough for $\mathrm{Kr}-85$ to permeate. In this way, $\mathrm{Kr}-85$ gas radionuclides could be completely separated from nitrogen and oxygen molecules by P-7 NPGO membranes. When the pore size was P-10, thirteen $\mathrm{Kr}-85$ molecules permeated through the pores during $10 \mathrm{~ns}$ simulation and the corresponding numbers of oxygen and nitrogen molecules were five and three, respectively. When the pore size was P-12, nitrogen and oxygen molecules permeated the nanoporous graphene. When nitrogen and oxygen molecules were not blocked by the pores (i.e., for P-10 or larger), there were more oxygen molecules permeating through the NPGO membrane than nitrogen molecules.

\section{References}

[1] Cimbák Ц̆ , Povinec P. ${ }^{85} \mathrm{Kr}$ atmospheric concentration in Bratislava from 1980 to 1983. Environ Int, 11, 65 (1985). http://dx.doi org/10.1016/0160-4120(85)90103-5.

[2] Yu M, Noble RD, Falconer JL. Zeolite membranes: microstructure characterization and permeation mechanisms. Acc Chem Res, 44, 
1196 (2011). http://dx.doi.org/10.1021/ar200083e.

[3] De Vos RM, Verweij H. High-Selectivity, High-flux silica membranes for gas separation. Science, 279, 1710 (1998). http:// dx.doi.org/10.1126/science.279.5357.1710.

[4] Shiflett MB, Foley HC. Ultrasonic deposition of high-selectivity nanoporous carbon membranes. Science, 285, 1902 (1999). http:// dx.doi.org/10.1126/science.285.5435.1902.

[5] Park HB, Jung CH, Lee YM, Hill AJ, Pas SJ, Mudie ST, Van Wagner E, Freeman BD, Cookson DJ. Polymers with cavities tuned for fast selective transport of small molecules and ions. Science, 318, 254 (2007). http://dx.doi.org/10.1126/science.1146744.

[6] Novoselov KS, Geim AK, Morozov SV, Jiang D, Zhang Y, Dubonos SV, Grigorieva IV, Firsov AA. Electric field effect in atomically thin carbon films. Science, 306, 666 (2004). http:// dx.doi.org/10.1126/science.1102896.

[7] Bunch JS, Verbridge SS, Alden JS, van der Zande AM, Parpia JM, Craighead HG, McEuen PL. Impermeable atomic membranes from graphene sheets. Nano Lett, 8, 2458 (2008). http://dx.doi. org/10.1021/nl801457b.

[8] Schrier J. Helium separation using porous graphene membranes. J Phys Chem Lett, 1, 2284 (2010). http://dx.doi.org/10.1021/ jz100748x.

[9] Du H, Li J, Zhang J, Su G, Li X, Zhao Y. Separation of hydrogen and nitrogen gases with porous graphene membrane. J Phys Chem C, 115, 23261 (2011). http://dx.doi.org/10.1021/jp206258u.

[10] Jiang D, Cooper VR, Dai S. Porous graphene as the ultimate membrane for gas separation. Nano Lett, 9, 4019 (2009). http://dx.doi. org/10.1021/n19021946.

[11] Tao Y, Xue Q, Liu Z, Shan M, Ling C, Wu T, Li X. Tunable hydrogen separation in porous graphene membrane: first-principle and molecular dynamic simulation. ACS Appl Mater Interfaces, $\mathbf{6}$, 8048 (2014). http://dx.doi.org/10.1021/am4058887.

[12] Lei G, Liu C, Xie H, Song F. Separation of the hydrogen sulfide and methane mixture by the porous graphene membrane: effect of the charges. Chem Phys Lett, 599, 127 (2014). http://dx.doi. org/10.1016/j.cplett.2014.03.040.

[13] Blankenburg S, Bieri M, Fasel R, Müllen K, Pignedoli CA, Passerone D. Porous graphene as an atmospheric nanofilter. Small, $\mathbf{6}$, 2266 (2010). http://dx.doi.org/10.1002/smll.201001126

[14] Sun C, Boutilier MSH, Au H, Poesio P, Bai B, Karnik R, Hadjiconstantinou NG. Mechanisms of molecular permeation through nanoporous graphene membranes. Langmuir, 30, 675 (2014). http://dx.doi.org/10.1021/la403969g.

[15] Freedman KJ, Ahn CW, Kim MJ. Detection of long and short DNA using nanopores with graphitic polyhedral edges. ACS Nano, 7, 5008 (2013). http://dx.doi.org/10.1021/nn4003665.

[16] Huh S, Park J, Kim YS, Kim KS, Hong BH, Nam JM. UV/ozoneoxidized large-scale graphene platform with large chemical enhancement in surface-enhanced Raman scattering. ACS Nano, 5, 9799 (2011). http://dx.doi.org/10.1021/nn204156n.

[17] Koenig SP, Wang L, Pellegrino J, Bunch JS. Selective molecular sieving through porous graphene. Nat Nanotechnol, 7, 728 (2012). http://dx.doi.org/10.1038/nnano.2012.162.

[18] Bagri A, Mattevi C, Acik M, Chabal YJ, Chhowalla M, Shenoy VB. Structural evolution during the reduction of chemically derived graphene oxide. Nat Chem, 2, 581 (2010). http://dx.doi. org/10.1038/nchem.686.

[19] Dreyer DR, Park S, Bielawski CW, Ruoff RS. The chemistry of graphene oxide. Chem Soc Rev, 39, 228 (2010). http://dx.doi.
org/10.1039/B917103G.

[20] Kim JE, Han TH, Lee SH, Kim JY, Ahn CW, Yun JM, Kim SO. Graphene oxide liquid crystals. Angew Chem Int Ed, 50, 3043 (2011). http://dx.doi.org/10.1002/anie.201004692.

[21] Chen D, Feng H, Li J. Graphene oxide: preparation, functionalization, and electrochemical applications. Chem Rev, 112, 6027 (2012). http://dx.doi.org/10.1021/cr300115g.

[22] Zhu Y, James DK, Tour JM. New routes to graphene, graphene oxide and their related applications. Adv Mater, 24, 4924 (2012). http://dx.doi.org/10.1002/adma.201202321.

[23] Kuila T, Mishra AK, Khanra P, Kim NH, Lee JH. Recent advances in the efficient reduction of graphene oxide and its application as energy storage electrode materials. Nanoscale, 5, 52 (2013). http:// dx.doi.org/10.1039/c2nr32703a.

[24] Smith SC, Ahmed F, Gutierrez KM, Frigi Rodrigues D. A comparative study of lysozyme adsorption with graphene, graphene oxide, and single-walled carbon nanotubes: potential environmental applications. Chem Eng J, 240, 147 (2014). http:// dx.doi.org/10.1016/j.cej.2013.11.030

[25] Dreyer DR, Jia HP, Bielawski CW. Graphene oxide: a convenient carbocatalyst for facilitating oxidation and hydration reactions Angew Chem Int Ed, 49, 6813 (2010). http://dx.doi.org/10.1002/ anie. 201002160

[26] Burress JW, Gadipelli S, Ford J, Simmons JM, Zhou W, Yildirim T. Graphene oxide framework materials: theoretical predictions and experimental results. Angew Chem Int Ed, 49, 8902 (2010). http:// dx.doi.org/10.1002/anie.201003328.

[27] Chung C, Kim YK, Shin D, Ryoo SR, Hong BH, Min DH. Biomedical applications of graphene and graphene oxide. Acc Chem Res, 46, 2211 (2013). http://dx.doi.org/10.1021/ar300159f.

[28] Diggikar RS, Late DJ, Kale BB. Unusual morphologies of reduced graphene oxide and polyaniline nanofibers-reduced graphene oxide composites for high performance supercapacitor applications. RSC Adv, 4, 22551 (2014). http://dx.doi.org/10.1039/C3RA47834C.

[29] Mi B. Graphene oxide membranes for ionic and molecular sieving. Science, 343, 740 (2014). http://dx.doi.org/10.1126/science. 1250247

[30] Joshi RK, Carbone P, Wang FC, Kravets VG, Su Y, Grigorieva IV, Wu HA, Geim AK, Nair RR. Precise and ultrafast molecular sieving through graphene oxide membranes. Science, 343, 752 (2014). http://dx.doi.org/10.1126/science.1245711.

[31] Kim HW, Yoon HW, Yoon SM, Yoo BM, Ahn BK, Cho YH, Shin HJ, Yang H, Paik U, Kwon S, Choi JY, Park HB. Selective gas transport through few-layered graphene and graphene oxide membranes. Science, 342, 91 (2013). http://dx.doi.org/10.1126/science. 1236098.

[32] Li H, Song Z, Zhang X, Huang Y, Li S, Mao Y, Ploehn HJ, Bao $\mathrm{Y}, \mathrm{Yu}$ M. Ultrathin, molecular-sieving graphene oxide membranes for selective hydrogen separation. Science, 342, 95 (2013). http:// dx.doi.org/10.1126/science.1236686.

[33] Nair RR, Wu HA, Jayaram PN, Grigorieva IV, Geim AK. Unimpeded permeation of water through helium-leak-tight graphene-based membranes. Science, 335, 442 (2012). http://dx.doi org/10.1126/science.1211694.

[34] Peigney A, Laurent C, Flahaut E, Bacsa RR, Rousset A. Specific surface area of carbon nanotubes and bundles of carbon nanotubes. Carbon, 39, 507 (2001). http://dx.doi.org/10.1016/S00086223(00)00155-X

[35] Guo YN, Lu X, Weng J, Leng Y. Density functional theory study 
of the interaction of arginine-glycine-aspartic acid with graphene, defective graphene, and graphene oxide. J Phys Chem C, 117, 5708 (2013). http://dx.doi.org/10.1021/jp310088e.

[36] Plimpton S. Fast parallel algorithms for short-range molecular dynamics. J Comput Phys, 117, 1 (1995). http://dx.doi.org/10.1006/ jcph.1995.1039.

[37] Humphrey W, Dalke A, Schulten K. VMD: Visual molecular dynamics. J Mol Graphics, 14, 33 (1996). http://dx.doi. org/10.1016/0263-7855(96)00018-5.

[38] Shih CJ, Lin S, Sharma R, Strano MS, Blankschtein D. Understanding the $\mathrm{pH}$-dependent behavior of graphene oxide aqueous solutions: a comparative experimental and molecular dynamics simulation study. Langmuir, 28, 235 (2012). http://dx.doi. org/10.1021/la203607w.

[39] Hoover WG. Canonical dynamics: equilibrium phase-space distributions. Phys Rev A, 31, 1695 (1985). http://dx.doi.org/10.1103/ PhysRevA.31.1695.

[40] Lennard-Jones JE. Cohesion. Proc Phys Soc, 43, 461 (1931). http:// dx.doi.org/10.1088/0959-5309/43/5/301.

[41] Cervellera VR, Albertí M, Huarte-larrañaga F. A molecular dynamics simulation of air adsorption in single-walled carbon nanotube bundles. Int J Quantum Chem, 108, 1714 (2008). http://dx.doi. org/10.1002/qua.21590.

[42] Foroutan M, Taghavi Nasrabadi A. Adsorption and separation of binary mixtures of noble gases on single-walled carbon nanotube bundles. Physica E, 43, 851 (2011). http://dx.doi.org/10.1016/j. physe.2010.10.011.

[43] Forester TR, Smith W. SHAKE, rattle, and roll: efficient constraint algorithms for linked rigid bodies. J Comput Chem, $19, \quad 102 \quad$ (1998). http://dx.doi.org/10.1002/(SICI)1096987X(19980115) 19:1<102::AID-JCC9>3.0.CO;2-T.

[44] Darden T, York D, Pedersen L. Particle mesh Ewald: An N · $\log (\mathrm{N})$ method for Ewald sums in large systems. J Chem Phys, 98, 10089 (1993). http://dx.doi.org/10.1063/1.464397.

[45] Wang JC, Fichthorn KA. A method for molecular dynamics simulation of confined fluids. J Chem Phys, 112, 8252 (2000). http:// dx.doi.org/10.1063/1.481430.

[46] Arora G, Wagner NJ, Sandler SI. Adsorption and diffusion of molecular nitrogen in single wall carbon nanotubes. Langmuir, $\mathbf{2 0}$, 6268 (2004). http://dx.doi.org/10.1021/la036432f.

[47] Suk ME, Aluru NR. Water transport through ultrathin graphene. J Phys Chem Lett, 1, 1590 (2010). http://dx.doi.org/10.1021/ jz100240r.

[48] Schrier J, McClain J. Thermally-driven isotope separation across nanoporous graphene. Chem Phys Lett, 521, 118 (2012). http:// dx.doi.org/10.1016/j.cplett.2011.11.069.

[49] Li Y, Zhou Z, Shen P, Chen Z. Two-dimensional polyphenylene: experimentally available porous graphene as a hydrogen purification membrane. Chem Commun, 46, 3672 (2010). http://dx.doi. org/10.1039/B926313F. 